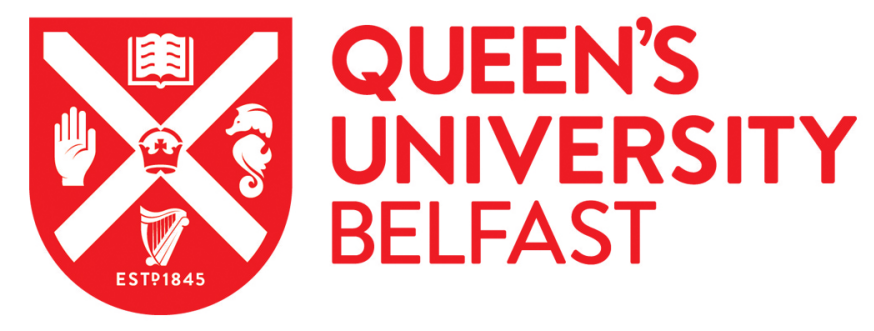

\title{
Circulating Sex Hormones Are Associated With Gastric and Colorectal Cancers but Not Esophageal Adenocarcinoma in the UK Biobank
}

McMenamin, Ú., Liu, P., Kunzmann, A., Cook, M., Coleman, H., Johnston, B., Cantwell, M., \& Cardwell, C. (2020). Circulating Sex Hormones Are Associated With Gastric and Colorectal Cancers but Not Esophageal Adenocarcinoma in the UK Biobank. The American Journal of Gastroenterology, 2020, 1. https://doi.org/10.14309/ajg.0000000000001045

Published in:

The American Journal of Gastroenterology

Document Version:

Peer reviewed version

Queen's University Belfast - Research Portal:

Link to publication record in Queen's University Belfast Research Portal

Publisher rights

(C) 2020 by The American College of Gastroenterology.

This work is made available online in accordance with the publisher's policies. Please refer to any applicable terms of use of the publisher.

\section{General rights}

Copyright for the publications made accessible via the Queen's University Belfast Research Portal is retained by the author(s) and / or other copyright owners and it is a condition of accessing these publications that users recognise and abide by the legal requirements associated with these rights.

Take down policy

The Research Portal is Queen's institutional repository that provides access to Queen's research output. Every effort has been made to ensure that content in the Research Portal does not infringe any person's rights, or applicable UK laws. If you discover content in the Research Portal that you believe breaches copyright or violates any law, please contact openaccess@qub.ac.uk. 
1 Circulating Sex Hormones are Associated with Gastric and Colorectal Cancer but not

2 Esophageal Adenocarcinoma in the UK Biobank

4 Short title: Sex Hormones and Gastrointestinal Cancer Risk

5

6 Úna C. McMenamin ${ }^{1}$, Peipei Liu ${ }^{1}$, Andrew T. Kunzmann ${ }^{1}$, Michael B. Cook ${ }^{2}$, Helen G.

7 Coleman ${ }^{1,3}$, Brian T. Johnston ${ }^{4}$, Marie M. Cantwell ${ }^{5}$, Chris R. Cardwell ${ }^{1}$.

8

$9 \quad{ }^{1}$ Centre for Public Health, Queen's University Belfast, Belfast, Northern Ireland, United 10 Kingdom.

$11{ }^{2}$ Division of Cancer Epidemiology and Genetics, National Cancer Institute, NIH, DHHS, 12 Bethesda, MD, USA.

${ }^{3}$ Centre for Cancer Research and Cell Biology, Queen's University Belfast, Northern Ireland,

United Kingdom.

${ }^{4}$ Department of Gastroenterology, Royal Victoria Hospital, Belfast Health \& Social Care Trust, Belfast, Northern Ireland, United Kingdom.

$17{ }^{5}$ Nutrition and Metabolism Group, Institute for Global Food Security, Queen's University Belfast, Belfast, Northern Ireland, United Kingdom.

\section{Corresponding author:}

21 Dr Úna McMenamin, Institute of Clinical Sciences Block B, Queen’s University Belfast, Royal 
Grant support:

Access to the UK Biobank was funded by a Cancer Research UK Population Research Postdoctoral Fellowship awarded to ÚCM. PL is supported by a joint scholarship from Queen's University of Belfast and the Chinese Scholarship Council (201708060458). HGC is supported by a Cancer Research UK Career Establishment Award.

\section{Acknowledgements:}

This research has been conducted using the UK Biobank Resource under Application Number 34374. The authors would like to acknowledge the contribution from Professor Liam Murray, who sadly passed away in January 2018.

\section{Guarantor of article: ÚMcM}

\section{Specific author contributions:}

Funding acquisition: ÚCM, CRC, BTJ, MBC; data acquisition: ÚCM; HGC, CRC; study design: ÚCM, CRC, HGC, MBC; data cleaning and analysis: ÚCM, PL, ATK, CRC; writing original draft: ÚCM; writing, review \& editing: all authors. All authors approved the final version of the manuscript.

\section{Conflicts of interest:}

The authors have no conflicts of interest to disclose.

\section{Word count:}

Main text: 3,000

Abstract (max 250): 250 
HIGHLIGHTS

50

51

52

53

54

55

56

57

58

59

60

- Gastrointestinal cancers show an unexplained male predominance in incidence

- Few prospective studies have investigated sex hormones and gastrointestinal cancer risk

\section{WHAT IS NEW HERE}

- Men with higher SHBG concentrations had higher gastric yet lower colorectal, cancer risks

- Women with higher free testosterone levels had lower risk of esophageal squamous cell carcinoma and colorectal cancer

- Additional prospective studies, particularly among women, are required to verify our novel findings 
Gastrointestinal cancers show an unexplained male predominance, but few prospective studies have investigated sex hormones and gastrointestinal cancer risk.

Aims: To determine the impact of circulating sex hormones on risk of esophageal, gastric and colorectal cancer in men and women. Methods:

We included 219,425 men and 147,180 women from UK Biobank. Sex hormones were quantified using chemiluminescent immunoassay. Gastrointestinal cancers were identified from cancer registry linkages. Sex hormone concentrations and risk of gastrointestinal cancers were investigated using Cox proportional hazards regression.

\section{Results:}

During 10 years of follow-up, 376 esophageal adenocarcinoma, 108 esophageal squamous cell carcinoma, 333 gastric and 2,868 colorectal cancer cases were identified. Increased hazard ratios (HRs) were found for sex hormone-binding globulin (SHBG) and risk of gastric cancer in men (Q4 v. Q1 HR 1.43, 95\% CI 0.95, 2.17, $\left.\mathrm{P}_{\text {trend }}=0.01\right)$. Free testosterone was inversely associated with esophageal squamous cell carcinoma in women (Q4 v. Q1 HR 0.32, 95\% CI $\left.0.11,0.98, \mathrm{P}_{\text {trend }}=0.05\right)$. For colorectal cancer, $\mathrm{SHBG}$ was associated with a reduced risk among men (Q4 v. Q1 HR 0.89, 95\% CI 0.77, 1.03, $\left.\mathrm{P}_{\text {trend }}=0.04\right)$ and free testosterone concentrations a reduction in risk among women (Q4 v. Q1 HR 0.80, 95\% CI 0.66, 0.97, $\left.\mathrm{P}_{\text {trend }}=0.01\right)$. No associations were found for esophageal adenocarcinoma.

Conclusion:

In this large prospective investigation of prediagnostic sex hormones and risk of gastrointestinal cancers, men with higher SHBG concentrations had higher gastric, yet lower colorectal, cancer risks while women with higher free testosterone levels had lower risk of esophageal squamous cell carcinoma and colorectal cancer. 
87 Keywords: sex hormones; gastrointestinal cancer; cohort study; UK Biobank 
Introduction:

91 Esophageal, gastric and colorectal cancer show an unexplained male predominance, which is

most marked for esophageal adenocarcinoma, where incidence is up to eight times higher in men than women (1). Established risk factors such as smoking and obesity do not fully explain the observed disparity in incidence $(2,3)$, which has led to the hypothesis that sex hormones, including estrogens and androgens, may be involved in the development of these cancers.

Epidemiological studies investigating the impact of exogenous sex hormone exposure report a 20 to $40 \%$ reduction in risk of esophageal adenocarcinoma $(4,5)$, esophageal squamous cell carcinoma $(6,7)$ gastric $(8)$ and colorectal $(5,9)$ cancer in women who use oral contraceptives or menopausal hormone therapy. In men, androgen deprivation therapy (ADT) use has been associated with a 30 to $40 \%$ increase in colorectal cancer risk, suggesting a potentially beneficial impact of androgens (10). In contrast, lower rates of esophageal adenocarcinoma (11) and squamous cell carcinoma (12) have been identified in men with prostate cancer, likely undergoing androgen deprivation therapy, suggesting androgens may be detrimental.

To date, there have been just two prospective studies of prediagnostic circulating sex hormones and risk of upper gastrointestinal cancers. Combined, these studies provide evidence for an inverse association between endogenous circulating testosterone and esophageal adenocarcinoma risk $(13,14)$, but there was less evidence for inverse associations of estradiol, luteinizing hormone (LH), and dehydroepiandrosterone (DHEA) with esophageal adenocarcinoma (15). Meanwhile, no study has specifically investigated risk of esophageal squamous cell carcinoma or gastric cancer with respect to prediagnostic circulating sex hormones. 
115 Colorectal cancer also shows a male predominance in incidence though not as marked as that seen for gastro-esophageal cancer. Some (16), but not all (17), studies of prediagnostic sex hormone concentrations in women have reported reductions in colorectal cancer risk with higher estradiol concentrations, while increases have been observed for higher testosterone (18) and sex hormone-binding globulin (SHBG) (16), a hepatically derived glycoprotein and primary transport protein of sex hormones. Only one study has evaluated circulating sex hormones and colorectal cancer risk in men and showed inverse associations with circulating testosterone and SHBG (19).

Further prospective investigation of the role of sex hormones in the development of gastrointestinal cancers may identify novel targets for prevention and treatment. We therefore aimed to conduct the first study to evaluate prediagnostic circulating sex hormones, in both men and women, and risk of esophageal, gastric and colorectal cancer in a large prospective cohort.

\section{Methods}

\section{Study Population}

The UK Biobank is a cohort of over 500,000 men and women aged 40-69 years recruited across England, Scotland and Wales between 2006 and 2010 (20). Data collection at baseline included lifestyle, medical history and physical measures, along with biological samples. UK Biobank is linked to cancer registry data from the Health and Social Care Information Centre (England and Wales) and the Scottish Cancer Registry (Scotland) and death records from the UK Office of National Statistics. Completeness of UK cancer registries has been shown to be high (21). and participants provided written informed consent. 


\section{Study design}

142 We conducted a prospective cohort study among males and postmenopausal females in the UK

143 Biobank. Women who reported current use of menopausal hormone therapy were excluded.

144 Gastrointestinal cancers included esophageal (International Classification of Diseases, ICD, 10 code C15), gastric (ICD 10 code C16) and colorectal (ICD 10 code 18-20). Esophageal and gastric cancers were further classified by histology, as adenocarcinoma (ICD-O morphology codes 8140-8573) or squamous cell carcinoma (ICD-O code 8050-8082). Gastric and colorectal cancers were classed by location, where possible, as cancers of the gastric cardia (ICD 10 code $\mathrm{C} 16.0$ ) and gastric non-cardia (ICD 10 code C16.1-16.5), colon (ICD 10 code C18, C19) and rectum (ICD 10 codes C20), respectively. Participants with a cancer diagnosis (except non-melanoma skin cancer) prior to baseline were excluded. The cohorts were followed from baseline to the date of first incident cancer or censoring on the earliest of death or March $30^{\text {th }} 2016$.

\section{Sample Collection and laboratory assays}

During the baseline visit, UK Biobank phlebotomists or nurses collected fasting blood samples from all participants at assessment centers. Blood samples were frozen at $-80^{\circ} \mathrm{C}$. SHBG, testosterone and estradiol, were analyzed by chemiluminescent immunoassay (Beckman Coulter, UK, Ltd) at the UK Biobank central laboratory in Stockport, UK. Internal quality control samples of known high, medium and low biomarker concentrations were run prior to each batch of participant samples and after each batch. In these quality controls, coefficients of variation $(\mathrm{CVs})$ were less than $16 \%$ (range $=5.2 \%$ to $15.3 \%)$. The UK Biobank sampling and handling methods have been shown to be robust (22). 


\section{Sex hormone measurements}

166 Free testosterone was calculated using previously validated methods (23). In all analyses, we replaced values below the lower limit of quantification (LOQ) with half the lower limit of quantification for SHBG $(0.2 \%$ men, $0.2 \%$ women $)$, testosterone $(0.2 \%$ men, $18 \%$ women $)$ and estradiol (91\% men, 96\% women), an approach similar to previous investigations $(13,18)$. Expectedly, due to the inclusion of males and postmenopausal females, estradiol concentrations were below the LOQ for a large proportion of the cohort. We categorised sex hormones into fourths based upon quartiles for SHBG, testosterone and free testosterone while for estradiol, values below the LOQ were categorized into the low group and the remainder were grouped into the high group.

\section{Covariates}

Interview and touch screen questionnaires at baseline were used to obtain information on covariates including age and sex, while lifestyle factors included smoking status (never smoker, former smoker or current smoker) and alcohol consumption (never, $<1$ day per week, 1-2 days per week, 3-4 days per week or $>4$ days per week). Body mass index (BMI), categorized as under or normal weight $\left[<25 \mathrm{~kg} / \mathrm{m}^{2}\right]$, overweight $\left[25-30 \mathrm{~kg} / \mathrm{m}^{2}\right]$, obese $\left[>30 \mathrm{~kg} / \mathrm{m}^{2}\right]$ ), was calculated from height and weight measurements taken by research staff. Information on diabetes and medication use was retrieved from interview/touch screen. Socioeconomic deprivation was retrieved from Townsend score (24) based upon postcode of residence. 
187 Characteristics between cases and non-cases were compared using frequencies and percentages. Cox proportional hazards regression was used to calculate hazard ratios (HR) and 95\% confidence intervals (CIs) for associations between circulating sex hormones and risk of esophageal (adenocarcinoma or squamous), gastric and colorectal cancer. Age was the underlying time scale and individuals were considered at risk from birth and under observation from age at baseline, left truncated. Models were stratified by sex and contained age, deprivation, BMI, alcohol (except esophageal adenocarcinoma), smoking, diabetes and aspirin and statin use (colorectal cancer only). Schoenfeld residuals were checked to determine the proportional hazards assumption. Sub-group analysis was conducted by cancer site (gastric cardia or non-cardia, colon or rectal) and sensitivity analysis excluded participants with a gastrointestinal cancer diagnosis in first year after baseline and additional adjustment was made for processed meat and fruit and vegetable intake (gastric and colorectal cancer). We also presented our findings for esophageal adenocarcinoma risk in men and colorectal cancer risk in men and women with respect to previous studies (Figure, Supplemental Digital Content 1).

\section{Results:}

We included 220,150 males and 147,180 females and during 10 years of follow-up, 376 esophageal adenocarcinoma (333 male, 43 female; M:F 5:1), 108 esophageal squamous cell carcinoma (57 male, 51 female; M:F 0.7:1), 333 gastric (256 male, 77 female; M:F 2.2:1) and 2,868 colorectal (1,892 male, 976 female; M:F 1.3:1) cancer cases were identified. Characteristics of participants are listed in Tables 1 (males) and 2 (females). In males, cases were more likely to be older, be smokers, and have a higher BMI compared to non-cases, with the exception of esophageal squamous cell carcinoma cases who were more likely to have a lower BMI. Aside from esophageal adenocarcinoma, male cases were more likely to be alcohol drinkers while esophageal squamous cell carcinoma cases were more likely to live in deprived 
areas compared to non-cases. Men with esophageal adenocarcinoma, gastric and colorectal cancer were more likely to have diabetes and use aspirin and statins, Table 1. In females, esophageal squamous cell carcinoma cases were more likely to be older, alcohol drinkers and have a lower BMI. Women with gastric cancer were more likely to be alcohol drinkers, have diabetes while both gastric cancer colorectal cancer cases were more likely older, and use aspirin and statins, Table 2 .

The associations between circulating sex hormones and risk of gastrointestinal cancers are presented in Tables 3 and 4. We observed no associations between sex hormones and esophageal adenocarcinoma risk in either males or females comparing the highest to the lowest concentrations. Esophageal squamous cell carcinoma risk was reduced in females comparing the highest to the lowest free testosterone concentrations (HR 0.32, 95\% CI 0.11, 0.98, $\left.\mathrm{P}_{\text {trend }}=0.05\right)$ while no associations were observed in men. For gastric cancer, higher SHBG across fourths was associated with an increased risk in men (HR 1.43, 95\% CI 0.95, 2.17, $\mathrm{P}_{\text {trend }}=0.01$ ), Table 3. In contrast, higher SHBG was associated with reduced risk of colorectal cancer in men (Q4 v Q1 HR 0.89, 95\% CI 0.77, 1.04, $\left.\mathrm{P}_{\text {trend }}=0.04\right)$. There was a reduced risk of colorectal cancer in females, comparing the highest to the lowest testosterone and free testosterone concentrations (HR 0.83, 95\% CI 0.69, 1.00, $\mathrm{P}_{\text {trend }}=0.05$, HR 0.80, 95\% CI 0.66, $0.97, \mathrm{P}_{\text {trend }}=0.01$, respectively), Table 4 . No associations were noted for gastrointestinal cancers and estradiol in either sex comparing the highest to the lowest concentrations, although there was limited ability to study these associations in women due to small case numbers, Tables 3 and 4 .

Results remained similar in analysis by cancer sub-site (Supplemental Digital Content 2 and 3). In men, there was weak evidence of a reduced colon cancer risk comparing the highest to 

year after baseline (Tables, Supplemental Digital Content 4 and 5) and were unchanged for gastric and colorectal cancer after additional adjustment for processed meat and fruit and vegetable intake (data not shown).

\section{Discussion:}

244 In our prospective analysis of prediagnostic sex hormones in both men and women, we found that SHBG was positively associated with gastric cancer risk in men and free testosterone was inversely associated with esophageal squamous cell carcinoma in women. For colorectal cancer, higher SHBG in men and testosterone concentrations in women were associated with a reduction in risk.

Although esophageal adenocarcinoma is the most male predominant cancer, we did not find any significant association between prediagnostic sex hormone concentrations and risk in men or women. Our results contrasts two prior cohort studies which in combination indicated an inverse association between testosterone and esophageal adenocarcinoma risk $(13,14)$ (Figure, Supplemental Digital Content 1). The US-based study (13) used mass spectrometry to quantitate estradiol, finding evidence for an inverse association with esophageal/gastric cardia adenocarcinoma, but the Norwegian study (14), which used an immunoassay with $36 \%$ of samples below the lower limit of detection, was not able to replicate this result. Individual results from these prior studies also support inverse associations of DHEA and LH with esophageal/gastric cardia adenocarcinoma, and these observations merit follow-up in other cohorts, as well as expansion to women, despite the greater rarity of these cancers in this sex. 
262 We found a reduced risk of esophageal squamous cell carcinoma in women with higher levels

263

264

265

266

267

268

269

270

271

272

273

274

275

of free testosterone, and a similar reduction for testosterone, but not statistically significant, suggesting that sex hormone modulation may be beneficial in high-risk females. However, the underlying biological mechanisms linking sex hormones and esophageal squamous cell carcinoma are not well understood. Expression of both estrogen receptor $\beta$ and androgen receptors have been shown in esophageal squamous cell carcinoma tissues $(25,26)$ and in vitro evidence has demonstrated growth promoting effects for testosterone in esophageal squamous cell carcinoma cell lines (27). Despite this, no previous study has investigated risk of esophageal squamous cell carcinoma with respect to circulating prediagnostic circulating sex hormones.

Similarly, no study has specifically investigated gastric cancer risk with respect to sex hormone levels, despite a two-fold higher incidence in men compared to women (28). We found an increased risk of gastric cancer in men with higher circulating concentrations of SHBG. Polymorphisms in SHBG, and well as COMT (involved in estrogen inactivation) have been associated with gastric cancer risk (29) and epidemiological studies in women have shown some protective associations for longer years of fertility and use of hormone replacement therapy, suggesting that estrogen may be protective (8). Higher SHBG levels have been hypothesised to reduce concentrations of free estrogen, which in turn may promote gastric cancer development (30) but we found no association with estradiol concentrations and gastric cancer risk in men, and we were unable to conduct analysis of estradiol in women due to small numbers. Although SHBG plays an integral role in the regulation of free estradiol and testosterone in circulation, it may have biological functions independent of sex hormone binding (31). Given the limited evidence, our novel findings for both gastric cancer and esophageal squamous cell carcinoma require verification in other prospective cohorts to 
determine potential applications of sex hormones or analogs in the prevention of these cancers. Future studies will require collaborative pooling of cohorts to ensure sufficient sample sizes, particularly for women.

We found weak evidence of a reduction in colorectal cancer risk in men with increasing levels of SHBG which is similar to the findings from the only prior investigation within the Health Professional Follow-Up Study (19), indicating that SHBG may have potential as a target in future colorectal cancer prevention studies in men. In women, our finding of a reduced colorectal cancer risk with higher concentrations of testosterone and free testosterone contrasts a Japanese nested case-control study that reported a doubling of risk with the highest testosterone levels and no significant association for free testosterone concentrations (Figure, Supplemental Digital Content 1) but more than $60 \%$ of participants had testosterone levels lower than LOQ (18). Differences in ethnicity may also explain discrepancies and we also included considerably more colorectal cancer cases (1,131 cases versus 185 cases (18)). In men, we found suggestive evidence that testosterone concentrations were inversely associated with colorectal cancer, similar to the only previously conducted study (19); however, our estimate was weaker and did not reach statistical significance. Preclinical evidence suggests that androgens exert protective effects against colorectal carcinogenesis; expression of androgen receptors in colorectal cancer tissue has been shown to be lower than that found in normal mucosa $(32,33)$ and administration of androgens protects against colorectal cancer in in vivo studies $(34,35)$. Use of ADT in men with prostate cancer has been associated with a 30$40 \%$ higher risk of colorectal cancer (10). Further large prospective investigations are needed to extend our findings, given the accumulating evidence of a potentially beneficial effect of androgens in colorectal cancer carcinogenesis. 
312 Our lack of association between estradiol concentrations and risk of colorectal cancer in women 313 is similar to four previous population-based studies $(17-19,36)$ but contrasts two US studies $314(16,37)$ (Figure, Supplemental Digital Content 1). A case-control study nested in the Women's 315 Health Initiative (WHI) Clinical Trial reported a 42-57\% reduced risk in women with the 316 highest concentrations of estradiol, free estradiol and estrone concentrations (16), while a casecohort study in the WHI-Observational Study observed a 53\% increased risk in women with the highest estradiol levels (37). Although these studies included considerably fewer colorectal cancer cases, divergent results may be due to differences in study design and hormone assays utilised. Circulating estrone levels were positively associated with risk of colorectal cancer in a nested case-control study in the New York University Women's Health Study, but no association was apparent for estradiol (36). Estrone is biologically weaker than estradiol but is found in higher quantities in postmenopausal women, therefore future studies should aim to also incorporate measurements of this hormone, especially in postmenopausal women.

Our study is the largest to date and for the first time in a cohort, we were able to include both men and women but some analysis in women, particularly estradiol, were limited by reduced numbers. A strength was that serum samples were collected up to 10 years prior to cancer, reducing potential reverse causation. Selection bias was limited as sex hormones were measured in the whole study population and we were able to investigate a number of adenocarcinoma cancer in women.

As described, a large proportion of participants had estradiol levels below the LOQ, which is expected in males and postmenopausal females using chemiluminescent immunoassay and 
although we replaced these values with half of the LOQ value, the resultant dichotomized exposure may have attenuated associations preventing us from replicating results of some studies. Testosterone and SHBG values were available for most participants (testosterone: 93\% males, $78 \%$ females; SHBG: $86 \%$ males, $84 \%$ females). The UK Biobank participants are generally healthier compared to the UK population, but risk factor-disease estimations are generalizable (38). Sex hormone concentrations were measured at one time-point but serum samples have shown good correlation with concentrations up to three years after baseline (39). We cannot rule out potential residual confounding, for example, pack-years of smoking, duration of diabetes, colonoscopy (colorectal cancer), or H. pylori (gastric cancer). We used an area-based deprivation measure, which is relatively crude however; it is likely be a proxy for other confounders associated with deprivation. Finally, a number of associations were investigated therefore increasing the chance of Type 1 error.

\section{Conclusion}

In a large prospective cohort study of prediagnostic sex hormones and risk of gastrointestinal cancers in men and women, we found evidence that higher levels of SHBG were associated with a higher risk of gastric cancer, but lower risk of colorectal cancer, in men. Free testosterone was associated with a reduction in colorectal cancer and esophageal squamous cell carcinoma in women. Additional prospective studies, particularly among women, are required to verify our novel findings in order to determine the utility of sex hormone modulation in the prevention of gastrointestinal cancers. 
Figure, Supplemental Digital Content 1. Forest plot of risk estimates comparing the highest vs the lowest concentrations of sex hormone levels from previous prospective studies and risk of (a) esophageal/gastric cardia adenocarcinoma in men, (b) colorectal cancer in men and (c) colorectal cancer in women.

${ }^{\text {a}}$ Referent category contains values below the limit of detection and the other two groups of approximately equal sizes for the remaining values.

${ }^{b}$ Referent category contains values below the limit of detection and the remainder were grouped into the high group.

CI, confidence interval; OR, odds ratio; HR, hazards ratio SHBG, sex hormone-binding globulin; Q, Quartile; T, tertile.

Table, Supplemental Digital Content 2. Prediagnostic sex hormone concentrations and gastrointestinal cancer sub-types in men in the UK Biobank.

Table, Supplemental Digital Content 3. Prediagnostic sex hormone concentrations and gastrointestinal cancer sub-types in women in the UK Biobank.

Table, Supplemental Digital Content 4. Prediagnostic sex hormone concentrations and risk of gastrointestinal cancers in men with at least one year of follow-up in the UK Biobank.

Table, Supplemental Digital Content 5. Prediagnostic sex hormone concentrations and risk of gastrointestinal cancers in women with at least one year of follow-up in the UK Biobank. 
References:

382 1. Coleman HG, Xie S-H, Lagergren J. The Epidemiology of Esophageal Adenocarcinoma. Gastroenterology. 2018; 154:390-405.

2. Lagergren J, Lagergren P. Recent developments in esophageal adenocarcinoma. $C A$ Cancer J Clin. 2013; 63:232-48.

3. Löfdahl HE, Lu Y, Lagergren J. Sex-specific risk factor profile in oesophageal adenocarcinoma. Br J Cancer. 2008; 99:1506 - 1510.

4. Lagergren K, Lagergren J, Brusselaers N. Hormone replacement therapy and oral contraceptives and risk of oesophageal adenocarcinoma: A systematic review and metaanalysis. Int J Cancer. 2014; 135:2183-90.

5. Green J, Czanner G, Reeves G, et al. Menopausal hormone therapy and risk of gastrointestinal cancer: Nested case-control study within a prospective cohort, and metaanalysis. Int J Cancer. 2012; 130:2387-2396.

6. Brusselaers N, Maret-Ouda J, Konings P, et al. Menopausal hormone therapy and the risk of esophageal and gastric cancer. Int J Cancer. 2017; 140:1693-1699.

7. Freedman ND, Lacey $\mathrm{J} \mathrm{V}$, Hollenbeck AR, et al. The association of menstrual and reproductive factors with upper gastrointestinal tract cancers in the NIH-AARP cohort. Cancer. 2010; 116:1572-81.

8. Camargo MC, Goto Y, Zabaleta J, et al. Sex Hormones, Hormonal Interventions, and Gastric Cancer Risk: A Meta-analysis. Cancer Epidemiol Biomarkers Prev. 2012;

402 9. Song J, Jin Z, Han H, et al. Hormone replacement therapies, oral contraceptives, reproductive factors and colorectal adenoma risk: a systematic review and dose- 
response meta-analysis of observational studies. Color Dis. 2019; 21:748-759.

405

406

407

408

409

410

411

412

413

414

415

416

417

10. Gillessen S, Templeton A, Marra G, et al. Risk of colorectal cancer in men on long-term androgen deprivation therapy for prostate cancer. J Natl Cancer Inst. 2010; 102:17601770.

11. Cooper SC, Croft S, Day R, et al. Patients with prostate cancer are less likely to develop oesophageal adenocarcinoma: could androgens have a role in the aetiology of oesophageal adenocarcinoma? Cancer Causes Control. 2009; 20:1363-8.

12. Cooper SC, Trudgill NJ. Subjects with prostate cancer are less likely to develop esophageal cancer: Analysis of SEER 9 registries database. Cancer Causes Control. 2012; 23:819-25.

13. Petrick JL, Hyland PL, Caron P, et al. Associations between prediagnostic concentrations of circulating sex steroid hormones and esophageal/gastric cardia adenocarcinoma among men. J Natl Cancer Inst. 2019; 111:34-41.

14. Xie SH, Ness-Jensen E, Rabbani S, et al. Circulating Sex Hormone Levels and Risk of Esophageal Adenocarcinoma in a Prospective Study in Men. Am J Gastroenterol. 2020; 115:216-223.

15. Petrick JL, Cook MB. Do sex hormones underlie sex differences in cancer incidence? Testing the intuitive in esophageal adenocarcinoma. Am J Gastroenterology. 2020; 115:211-213.

16. Murphy N, Strickler HD, Stanczyk FZ, et al. A Prospective Evaluation of Endogenous Sex Hormone Levels and Colorectal Cancer Risk in Postmenopausal Women. J Natl Cancer Inst. 2015; 107:1-10. 
17. Falk RT, Dallal CM, Lacey JV et al. Estrogen Metabolites Are Not Associated With Colorectal Cancer Risk in Postmenopausal Women. Cancer Epidemiol Biomarkers Prev. 2015; 24:1419-22.

18. Mori N, Sawada N, Iwasaki M, et al. Circulating sex hormone levels and colorectal cancer risk in Japanese postmenopausal women: The JPHC nested case-control study. Int J Cancer. 2019; 145:1238-1244.

19. Lin JH, Zhang SM, Rexrode KM, et al. Association between sex hormones and colorectal cancer risk in men and women. Clin Gastroenterol Hepatol. 2013; 11:419424.

20. Allen N, Sudlow C, Downey P, et al. UK Biobank: Current status and what it means for epidemiology. Heal Policy Technol. 2012; 1:123-126.

21. Møller H, Richards S, Hanchett N, et al. Completeness of case ascertainment and survival time error in English cancer registries: Impact on 1-year survival estimates. $\mathrm{Br}$ J Cancer. 2011; 105:170-176.

22. Peakman TC, Elliott P. The UK Biobank sample handling and storage validation studies. Int J Epidemiol. 200; 37 Suppl 1:i2-6.

23. Vermeulen A, Verdonck L, Kaufman JM. A critical evaluation of simple methods for the estimation of free testosterone in serum. J Clin Endocrinol Metab. 1999; 84:36663672.

24. Townsend P. Deprivation. J Soc Policy. 1987; 16:125-146.

25. Kalayarasan R, Ananthakrishnan N, Kate V, et al. Estrogen and progesterone receptors in esophageal carcinoma. Dis Esophagus. 2008; 21:298-303.

26. Nozoe T, Oyama T, Takenoyama M, et al. Significance of immunohistochemical 
expression of estrogen receptors alpha and beta in squamous cell carcinoma of the esophagus. Clin Cancer Res. 2007; 13:4046-4050.

27. Matsuoka H, Sugimachi K, Ueo H, et al. Sex Hormone Response of a Newly Established Squamous Cell Line Derived from Clinical Esophageal Carcinoma. Cancer Res. 1987; 47:4134-4140.

28. Sipponen P, Correa P. Delayed rise in incidence of gastric cancer in females results in unique sex ratio (M/F) pattern: Etiologic hypothesis. Gastric Cancer. 2002; 5:213-219.

29. Freedman ND, Ahn J, Hou L, et al. Polymorphisms in estrogen- and androgenmetabolizing genes and the risk of gastric cancer. Carcinogenesis. 2009; 30:71-7.

30. Cheng CW, Chang CC, Patria YN, et al. Sex hormone-binding globulin (SHBG) is a potential early diagnostic biomarker for gastric cancer. Cancer Med. 2018; 7:64-74.

31. Rosner W, Hryb DJ, Kahn SM, et al. Interactions of sex hormone-binding globulin with target cells. Mol Cell Endocrinol. 2010; 316:79-85.

32. Castagnetta L, Traina A, Campisi I, et al. Androgen Receptor Status in Nontumoral and Malignant Human Colorectal Tissues. Ann N Y Acad Sci. 2002; 963:322-5.

33. Meggouh F, Lointier P, Saez S. Sex Steroid and 1,25-Dihydroxyvitamin D3 Receptors in Human Colorectal Adenocarcinoma and Normal Mucosa. Cancer Res. 1991; 51:1227-1233.

34. Izbicki JR, Hamilton SR, Wambach G, et al. Effects of androgen manipulations on chemically induced colonic tumours and on macroscopically normal colonic mucosa in male Sprague-Dawley rats. Br J Cancer. 1990; 61:235-240.

35. Rao CV, Tokumo K, Rigotty J, et al. Chemoprevention of Colon Carcinogenesis by Dietary Administration of Piroxicam, a-Difluoromethylornithine, 16a-Fluoro-5- 
36. Clendenen TV, Koenig KL, Shore RE, et al. Postmenopausal levels of endogenous sex hormones and risk of colorectal cancer. Cancer Epidemiol Biomarkers Prev. 2009; 18:275-281.

37. Gunter MJ, Hoover DR, Yu H, et al. Insulin, Insulin-like Growth Factor-I, Endogenous Estradiol, and Risk of Colorectal Cancer in Postmenopausal Women. Cancer Res. 2008; 68:329-337.

38. Batty GD, Gale CR, Kivimäki M, et al. Comparison of risk factor associations in UK Biobank against representative, general population based studies with conventional response rates: prospective cohort study and individual participant meta-analysis. $B M J$. 2020; 368:m131.

39. Hankinson SE, Manson JE, Willett WC, et al. Reproducibility of Plasma Hormone Levels in Postmenopausal Women over a 2-3-year Period. Cancer Epidemiol Biomarkers Prev. 1995; 4:649-654. 
Table 1. Characteristics of gastrointestinal cancer cases and non-cases among men in the UK Biobank

\begin{tabular}{|c|c|c|c|c|c|c|c|c|}
\hline & \multicolumn{2}{|c|}{ Esophageal adenocarcinoma } & \multicolumn{2}{|c|}{$\begin{array}{c}\text { Esophageal squamous cell } \\
\text { carcinoma }\end{array}$} & \multicolumn{2}{|c|}{ Gastric cancer } & \multicolumn{2}{|c|}{ Colorectal cancer } \\
\hline & $\begin{array}{l}\text { Cases } \\
\text { n (\%) }\end{array}$ & $\begin{array}{c}\text { Non-cases } \\
\text { n }(\%)\end{array}$ & $\begin{array}{l}\text { Cases } \\
\text { n (\%) } \\
\end{array}$ & $\begin{array}{c}\text { Non-cases } \\
\text { n }(\%)\end{array}$ & $\begin{array}{l}\text { Cases } \\
\text { n (\%) } \\
\end{array}$ & $\begin{array}{c}\text { Non-cases } \\
\text { n (\%) }\end{array}$ & $\begin{array}{l}\text { Cases } \\
\text { n (\%) } \\
\end{array}$ & $\begin{array}{c}\text { Non-cases } \\
\text { n (\%) }\end{array}$ \\
\hline \multicolumn{9}{|l|}{ Age at baseline } \\
\hline$<50$ & $11(3.3 \%)$ & $52,493(23.9 \%)$ & $3(5.3 \%)$ & $52,501(23.9 \%)$ & $18(7.0 \%)$ & $52,486(23.9 \%)$ & $104(5.5 \%)$ & $52,400(24.0 \%)$ \\
\hline $50-59$ & $91(27.3 \%)$ & $71,093(32.3 \%)$ & $17(29.8 \%)$ & $71,167(32.3 \%)$ & $54(21.1 \%)$ & $71,130(32.3 \%)$ & $507(26.8 \%)$ & $70,677(32.4 \%)$ \\
\hline $60-69$ & $225(67.6 \%)$ & $95,115(43.3 \%)$ & $34(59.6 \%)$ & $95,306(43.3 \%)$ & $177(69.1 \%)$ & $95,163(43.3 \%)$ & $1,260(66.6 \%)$ & $94,080(43.1 \%)$ \\
\hline $70+$ & $6(1.8 \%)$ & $1,116(0.5 \%)$ & $3(5.3 \%)$ & $1,119(0.5 \%)$ & $7(2.7 \%)$ & $1,115(0.5 \%)$ & $21(1.1 \%)$ & $1,101(0.5 \%)$ \\
\hline \multicolumn{9}{|l|}{ Deprivation } \\
\hline 1 (least deprived) & $63(18.9 \%)$ & $44,297(20.2 \%)$ & $5(8.6 \%)$ & $44,355(20.2 \%)$ & $42(16.4 \%)$ & $44,318(20.2 \%)$ & $409(21.6 \%)$ & $43,951(20.1 \%)$ \\
\hline 2 & $67(20.1 \%)$ & $43,727(19.9 \%)$ & $4(7.0 \%)$ & $43,790(19.9 \%)$ & $38(14.8 \%)$ & $43,756(19.9 \%)$ & $407(21.5 \%)$ & $43,387(19.9 \%)$ \\
\hline 3 & $58(17.4 \%)$ & $43,058(19.6 \%)$ & $14(24.6 \%)$ & $43,102(19.6 \%)$ & $52(20.3 \%)$ & 43,064 (19.6\%) & $358(18.9 \%)$ & $42,758(19.6 \%)$ \\
\hline 4 & $67(20.1 \%)$ & $43,319(19.7 \%)$ & $8(14.0 \%)$ & 43,378 (19.7\%) & $60(23.4 \%)$ & $43,326(19.7 \%)$ & $339(17.9 \%)$ & $43,047(19.7 \%)$ \\
\hline 5 (most deprived) & $78(23.4 \%)$ & $45,123(20.5 \%)$ & $26(45.6 \%)$ & $45,175(20.5 \%)$ & $63(24.6 \%)$ & $45,138(20.5 \%)$ & $378(20.0 \%)$ & $44,823(20.5 \%)$ \\
\hline Missing & $0(0.0 \%)$ & $293(0.1 \%)$ & $0(0.0 \%)$ & $293(0.1 \%)$ & $1(0.4 \%)$ & $292(0.1 \%)$ & $1(0.1 \%)$ & $292(0.1 \%)$ \\
\hline \multicolumn{9}{|l|}{ Smoking status } \\
\hline Never & $79(23.7 \%)$ & $107,501(48.9 \%)$ & $17(29.8 \%)$ & $107,563(48.9 \%)$ & $78(30.5 \%)$ & $107,502(48.9 \%)$ & $725(38.3 \%)$ & $106,855(49.0 \%)$ \\
\hline Former & $188(56.5 \%)$ & $83,294(37.9 \%)$ & $24(42.1 \%)$ & $83,458(37.9 \%)$ & $128(50.0 \%)$ & $83,354(37.9 \%)$ & $929(49.1 \%)$ & $82,553(37.8 \%)$ \\
\hline Current & $63(18.9 \%)$ & $27,658(12.6 \%)$ & $15(26.3 \%)$ & $27,706(12.6 \%)$ & $48(18.8 \%)$ & $27,673(12.6 \%)$ & $226(12.0 \%)$ & $27,495(12.6 \%)$ \\
\hline Missing & $3(0.9 \%)$ & $1,364(0.6 \%)$ & $1(1.8 \%)$ & $1,366(0.6 \%)$ & $2(0.8 \%)$ & $1,365(0.6 \%)$ & $12(0.6 \%)$ & $1,355(0.6 \%)$ \\
\hline \multicolumn{9}{|l|}{ Body mass index } \\
\hline Normal/underweight & $46(13.8 \%)$ & $54,984(25.0 \%)$ & $5(26.3 \%)$ & $55,015(25.0 \%)$ & $45(17.6 \%)$ & $54,985(25.0 \%)$ & $381(20.1 \%)$ & $54,649(25.0 \%)$ \\
\hline Overweight & $154(46.3 \%)$ & $107,739(49.0 \%)$ & $32(56.1 \%)$ & $107,861(49.0 \%)$ & $131(51.2 \%)$ & $107,762(49.0 \%)$ & $924(48.8 \%)$ & $106,969(49.0 \%)$ \\
\hline Obese & $130(39.0 \%)$ & $55,501(25.3 \%)$ & $8(14.0 \%)$ & $55,623(25.3 \%)$ & $79(30.9 \%)$ & $55,552(25.3 \%)$ & $573(30.3 \%)$ & $55,058(25.2 \%)$ \\
\hline Missing & $3(0.9 \%)$ & $1,593(0.7 \%)$ & $2(3.5 \%)$ & $1,594(0.7 \%)$ & $1(0.4 \%)$ & $1,595(0.7 \%)$ & $14(0.7 \%)$ & $1,582(0.7 \%)$ \\
\hline \multicolumn{9}{|l|}{ Alcohol consumption } \\
\hline Never (5) & $22(6.6 \%)$ & $13,902(6.3 \%)$ & $8(14.0 \%)$ & $13,916(6.3 \%)$ & $27(10.5 \%)$ & $13,897(6.3 \%)$ & $84(4.4 \%)$ & $13,840(6.3 \%)$ \\
\hline$<1$ day per wk (4) & $65(19.5 \%)$ & $35,648(16.2 \%)$ & $5(8.8 \%)$ & $35,708(16.2 \%)$ & $55(21.5 \%)$ & $35,658(16.2 \%)$ & $245(12.9 \%)$ & $35,468(16.3 \%)$ \\
\hline $1-2$ days per wk (3) & $91(27.3 \%)$ & $56,722(25.8 \%)$ & $6(10.5 \%)$ & $56,807(25.8 \%)$ & $65(25.4 \%)$ & $56,748(25.8 \%)$ & $463(24.5 \%)$ & $56,350(25.8 \%)$ \\
\hline 3-4 days per wk (2) & $71(21.3 \%)$ & $57,351(26.1 \%)$ & $18(31.6 \%)$ & $57,404(26.1 \%)$ & $45(17.6 \%)$ & $57,377(26.1 \%)$ & $511(27.0 \%)$ & $56,911(26.1 \%)$ \\
\hline$>4$ days per wk (1) & $82(24.6 \%)$ & $55,456(25.2 \%)$ & $19(33.3 \%)$ & $55,519(25.2 \%)$ & $63(24.6 \%)$ & $55,475(25.2 \%)$ & $584(30.9 \%)$ & $54,954(25.2 \%)$ \\
\hline Missing & $2(0.6 \%)$ & $738(0.3 \%)$ & $1(1.8 \%)$ & $739(0.3 \%)$ & $1(0.4 \%)$ & $739(0.3 \%)$ & $5(0.3 \%)$ & $735(0.3 \%)$ \\
\hline Diabetes & $48(14.4 \%)$ & $15,170(6.9 \%)$ & $3(5.3 \%)$ & $15,215(6.9 \%)$ & $29(11.3 \%)$ & $15,189(6.9 \%)$ & $201(10.6 \%)$ & $15,017(6.9 \%)$ \\
\hline Aspirin use & $85(25.5 \%)$ & $40,814(18.6 \%)$ & $14(24.6 \%)$ & $40,885(18.6 \%)$ & $80(31.3 \%)$ & $40,819(18.6 \%)$ & $441(23.3 \%)$ & $40,458(18.5 \%)$ \\
\hline Statin use & $115(34.5 \%)$ & $47,601(21.7 \%)$ & $18(31.6 \%)$ & $47,698(21.7)$ & $79(30.9)$ & $47,637(21.7)$ & $582(30.8)$ & $47,134(21.6)$ \\
\hline
\end{tabular}


Table 2. Characteristics of gastrointestinal cancer cases and non-cases among postmenopausal women in the UK Biobank

\begin{tabular}{|c|c|c|c|c|c|c|c|c|}
\hline & \multicolumn{2}{|c|}{ Esophageal adenocarcinoma } & \multicolumn{2}{|c|}{$\begin{array}{c}\text { Esophageal squamous cell } \\
\text { carcinoma }\end{array}$} & \multicolumn{2}{|c|}{ Gastric cancer } & \multicolumn{2}{|c|}{ Colorectal cancer } \\
\hline & $\begin{array}{l}\text { Cases } \\
\text { n (\%) }\end{array}$ & $\begin{array}{c}\text { Non-cases n } \\
(\%)\end{array}$ & $\begin{array}{l}\text { Cases } \\
\text { n (\%) }\end{array}$ & $\begin{array}{c}\text { Non-cases } \\
\text { n (\%) }\end{array}$ & $\begin{array}{l}\text { Cases } \\
\text { n (\%) }\end{array}$ & $\begin{array}{c}\text { Non-cases n } \\
(\%)\end{array}$ & $\begin{array}{l}\text { Cases } \\
\text { n (\%) }\end{array}$ & $\begin{array}{c}\text { Non-cases n } \\
(\%)\end{array}$ \\
\hline \multicolumn{9}{|l|}{ Age at baseline } \\
\hline$<50$ & $0(0.0 \%)$ & $3,976(2.7 \%)$ & $0(0 \%)$ & $3,976(2.7 \%)$ & $0(0.0 \%)$ & $3,976(2.7 \%)$ & $12(1.2 \%)$ & $3,964(2.7 \%)$ \\
\hline $50-59$ & $15(34.9 \%)$ & $56,368(38.3 \%)$ & $10(19.6 \%)$ & $56,373(38.3 \%)$ & $15(19.5 \%)$ & $56,368(38.3 \%)$ & $274(28.1 \%)$ & $56,109(38.4 \%)$ \\
\hline $60-69$ & $28(65.1 \%)$ & $85,903(58.4 \%)$ & $41(80.4 \%)$ & $85,890(58.4 \%)$ & $60(77.9 \%)$ & $85,871(58.4 \%)$ & $672(68.9 \%)$ & $85,259(58.3 \%)$ \\
\hline $70+$ & $0(0.0 \%)$ & $890(0.6 \%)$ & $0(0.0 \%)$ & $890(0.6 \%)$ & $2(2.6 \%)$ & $888(0.6 \%)$ & $18(1.8 \%)$ & $872(0.6 \%)$ \\
\hline \multicolumn{9}{|l|}{ Deprivation } \\
\hline 1 (least deprived) & $5(11.6 \%)$ & $30,415(20.7 \%)$ & $7(13.7 \%)$ & $30,413(20.7 \%)$ & $8(10.4 \%)$ & $30,412(20.7 \%)$ & $215(22.0 \%)$ & $30,205(20.7 \%)$ \\
\hline 2 & $8(18.6 \%)$ & $30,702(20.9 \%)$ & $14(27.5 \%)$ & $30,696(20.9 \%)$ & $17(22.1 \%)$ & $30,693(20.9 \%)$ & $218(22.3 \%)$ & $30,492(20.9 \%)$ \\
\hline 3 & $12(27.1 \%)$ & $30,246(20.6 \%)$ & $11(21.6 \%)$ & $30,247(20.6 \%)$ & $13(16.9 \%)$ & $30,245(20.6 \%)$ & $188(19.3 \%)$ & $30,070(20.5 \%)$ \\
\hline 4 & $6(13.9 \%)$ & $29,028(19.7 \%)$ & $7(13.7 \%)$ & $29,027(19.7 \%)$ & $19(24.7 \%)$ & $29,015(19.7 \%)$ & $181(18.6 \%)$ & $28,853(19.7 \%)$ \\
\hline 5 (most deprived) & $12(27.9 \%)$ & $26,596(18.1 \%)$ & $12(23.5 \%)$ & $26,596(18.1 \%)$ & $20(26.0 \%)$ & $26,588(18.1 \%)$ & $173(17.7 \%)$ & $26,435(18.1 \%)$ \\
\hline Missing & $0(0.0 \%)$ & $150(0.1 \%)$ & $0(0.0 \%)$ & $150(0.1 \%)$ & $0(0.0 \%)$ & $150(0.1 \%)$ & $1(0.1 \%)$ & $149(0.1 \%)$ \\
\hline \multicolumn{9}{|l|}{ Smoking status } \\
\hline Never & $18(41.9 \%)$ & $85,647(58.2 \%)$ & $26(51.0 \%)$ & $85,639(58.2 \%)$ & $47(61.0 \%)$ & $85,618(58.2 \%)$ & $545(55.8 \%)$ & $85,120(58.2 \%)$ \\
\hline Former & $19(44.2 \%)$ & 49,092 (33.4\%) & $18(35.3 \%)$ & 49,093 (33.4\%) & $23(29.9 \%)$ & $49,088(33.4 \%)$ & $354(36.3 \%)$ & $48,757(33.4 \%)$ \\
\hline Current & $6(13.9 \%)$ & $11,826(8.0 \%)$ & $7(13.7 \%)$ & $11,825(8.0 \%)$ & $6(7.8 \%)$ & $11,826(8.0 \%)$ & $75(7.7 \%)$ & $11,757(8.0 \%)$ \\
\hline Missing & $0(0.0 \%)$ & $872(0.4 \%)$ & $0(0.0 \%)$ & $572(0.4 \%)$ & $1(1.3 \%)$ & $571(0.4 \%)$ & $2(0.2 \%)$ & $570(0.4 \%)$ \\
\hline \multicolumn{9}{|l|}{ Body mass index } \\
\hline Normal/underweight & $13(30.2 \%)$ & $55,905(38.0 \%)$ & $25(49.0 \%)$ & $55,893(38.0 \%)$ & $31(40.3 \%)$ & $55,887(38.0 \%)$ & $351(36.0 \%)$ & $55,567(38.0 \%)$ \\
\hline Overweight & $16(37.2 \%)$ & $56,065(38.1 \%)$ & $20(39.2 \%)$ & $56,061(38.1 \%)$ & $28(36.4 \%)$ & $56,053(38.1 \%)$ & $386(39.5 \%)$ & $55,695(38.1 \%)$ \\
\hline Obese & $14(32.6 \%)$ & $34,461(23.4 \%)$ & $5(9.8 \%)$ & $34,470(23.4 \%)$ & $18(23.4 \%)$ & $34,457(23.4 \%)$ & $233(23.9 \%)$ & $34,242(23.4 \%)$ \\
\hline Missing & $0(0.0 \%)$ & $706(0.5 \%)$ & $1(2.0 \%)$ & $705(0.5 \%)$ & $0(0.0 \%)$ & $706(0.5 \%)$ & $6(0.6 \%)$ & $700(0.5 \%)$ \\
\hline \multicolumn{9}{|l|}{ Alcohol consumption } \\
\hline Never & $5(11.6 \%)$ & $14,687(10.0 \%)$ & $13(25.5 \%)$ & $14,679(10.0 \%)$ & $6(7.8 \%)$ & $14,686(10.0 \%)$ & $109(11.2 \%)$ & $14,583(10.0 \%)$ \\
\hline$<1$ day per wk & $15(34.9 \%)$ & $40,608(27.6 \%)$ & $12(23.5 \%)$ & $40,611(27.6 \%)$ & $24(31.2 \%)$ & $40,599(27.6 \%)$ & $281(28.8 \%)$ & $40,342(27.6 \%)$ \\
\hline $1-2$ days per wk & $11(25.6 \%)$ & $36,508(24.8 \%)$ & $6(11.8 \%)$ & $36,513(24.8 \%)$ & $21(27.3 \%)$ & $36,498(24.8 \%)$ & $236(24.2 \%)$ & $36,283(24.8 \%)$ \\
\hline 3-4 days per wk & $7(16.3 \%)$ & $29,790(20.2 \%)$ & $6(11.8 \%)$ & $29,791(20.3 \%)$ & $16(20.8 \%)$ & $29,781(20.2 \%)$ & $171(17.5 \%)$ & $29,626(20.3 \%)$ \\
\hline$>4$ days per wk & $5(11.6 \%)$ & $25,426(17.3 \%)$ & $14(27.4 \%)$ & $25,417(17.3 \%)$ & $9(11.7 \%)$ & $25,422(17.3 \%)$ & $178(18.2 \%)$ & $25,253(17.3 \%)$ \\
\hline Missing & $0(0.0 \%)$ & $118(0.1 \%)$ & $0(0.0 \%)$ & $118(0.1 \%)$ & $1(1.3 \%)$ & $117(0.1 \%)$ & $1(0.1 \%)$ & $117(0.1 \%)$ \\
\hline Diabetes & $3(7.0 \%)$ & $5,836(4.0 \%)$ & $2(3.9 \%)$ & $5,837(4.0 \%)$ & $9(11.7 \%)$ & $5,830(4.0 \%)$ & $50(5.1 \%)$ & $5,789(4.0 \%)$ \\
\hline Aspirin use & $3(7.0 \%)$ & $17,392(11.8 \%)$ & $6(11.8 \%)$ & $17,389(11.8 \%)$ & $17(22.1 \%)$ & $17,378(11.1 \%)$ & $136(13.9 \%)$ & $17,259(11.8 \%)$ \\
\hline Statin use & $7(16.3 \%)$ & $22,076(15.0 \%)$ & $9(17.7 \%)$ & $22,074(15.0 \%)$ & $19(24.7 \%)$ & $22,064(15.0 \%)$ & $180(18.4 \%)$ & $21,903(15.0 \%)$ \\
\hline
\end{tabular}


Table 3. Prediagnostic sex hormone concentrations and risk of gastrointestinal cancers in men in the UK Biobank

\begin{tabular}{|c|c|c|c|c|c|c|c|c|c|}
\hline \multirow[b]{2}{*}{ SHBG (nmol/L) } & \multirow[b]{2}{*}{$\begin{array}{c}\text { Person- } \\
\text { years }\end{array}$} & \multicolumn{2}{|c|}{$\begin{array}{c}\text { Esophageal } \\
\text { adenocarcinoma }\end{array}$} & \multicolumn{2}{|c|}{$\begin{array}{c}\text { Esophageal squamous } \\
\text { cell carcinoma }\end{array}$} & \multicolumn{2}{|c|}{ Gastric cancer } & \multicolumn{2}{|c|}{ Colorectal cancer } \\
\hline & & Cases & $\begin{array}{c}\text { Adjusted HR } \\
{(95 \% ~ C I)^{\dagger}}^{\dagger}\end{array}$ & Cases & $\begin{array}{c}\text { Adjusted HR } \\
(95 \% \mathrm{CI})^{\dagger}\end{array}$ & Cases & $\begin{array}{c}\text { Adjusted HR } \\
\left(_{(95 \%} \text { CI }\right)^{\dagger}\end{array}$ & Cases & $\begin{array}{c}\text { Adjusted HR } \\
{\text { (95\% CI })^{\dagger}}^{\dagger}\end{array}$ \\
\hline$<27.84$ & 331,099 & 56 & 1.00 & 8 & 1.00 & 39 & 1.00 & 356 & 1.00 \\
\hline 27.84 to $<36.86$ & 327,675 & 62 & $0.92(0.64,1.33)$ & 10 & $1.03(0.39,2.74)$ & 40 & $0.83(0.53,1.31)$ & 419 & $0.99(0.85,1.14)$ \\
\hline 36.86 to $<48.06$ & 325,641 & 77 & $1.10(0.78,1.57)$ & 13 & $1.09(0.43,2.81)$ & 67 & $1.37(0.91,2.07)$ & 394 & $0.84(0.72,0.97)$ \\
\hline$\geq 48.06$ & 321,946 & 84 & $1.15(0.80,1.64)$ & 19 & $1.24(0.49,3.13)$ & 78 & $1.43(0.95,2.17)$ & 452 & $0.89(0.77,1.04)$ \\
\hline \multicolumn{10}{|c|}{ Testosterone (nmol/L) } \\
\hline$<9.44$ & 352,334 & 102 & 1.00 & 9 & 1.00 & 64 & 1.00 & 505 & 1.00 \\
\hline 9.44 to $<11.63$ & 353,707 & 73 & $0.87(0.64,1.17)$ & 18 & $2.19(0.95,5.07)$ & 52 & $0.88(0.60,1.28)$ & 442 & $0.96(0.84,1.09)$ \\
\hline 11.63 to $<14.14$ & 354,207 & 72 & $0.93(0.68,1.27)$ & 9 & $1.05(0.40,2.76)$ & 62 & $1.16(0.81,1.66)$ & 437 & $0.99(0.87,1.13)$ \\
\hline$\geq 14.14$ & 353,475 & 63 & $0.90(0.65,1.26)$ & 19 & $2.14(0.91,5.01)$ & 60 & $1.24(0.85,1.79)$ & 362 & $0.88(0.77,1.02)$ \\
\hline Missing & & 23 & $\mathrm{P}_{\text {trend }}=0.62$ & 2 & $\mathrm{P}_{\text {trend }}=0.27$ & 18 & $\mathrm{P}_{\text {trend }}=0.14$ & 146 & $\mathrm{P}_{\text {trend }}=0.16$ \\
\hline \multicolumn{10}{|c|}{ Free testosterone (nmol/L) } \\
\hline 0.18 to $<0.21$ & 323,835 & 78 & $0.97(0.72,1.31)$ & 9 & $0.67(0.29,1.54)$ & 42 & $0.56(0.38,0.81)$ & 411 & $0.89(0.78,1.01)$ \\
\hline 0.21 to $<0.25$ & 326,815 & 60 & $0.90(0.65,1.25)$ & 14 & $1.12(0.53,2.37)$ & 51 & $0.88(0.62,1.26)$ & 360 & $0.91(0.79,1.04)$ \\
\hline$\geq 0.25$ & 329,622 & 38 & $0.79(0.54,1.17)$ & 12 & $1.32(0.60,2.92)$ & 40 & $0.90(0.60,1.34)$ & 302 & $0.99(0.86,1.15)$ \\
\hline Missing & & 56 & $P_{\text {trend }}=0.23$ & 7 & $P_{\text {trend }}=0.37$ & 36 & $P_{\text {trend }}=0.72$ & 278 & $P_{\text {trend }}=0.72$ \\
\hline \multicolumn{10}{|c|}{ Estradiol (pmol/L) } \\
\hline$<175.0$ & $1,205,119$ & 259 & 1.00 & 46 & 1.00 & 202 & 1.00 & 1506 & 1.00 \\
\hline$\geq 175.0$ & 122,367 & 31 & $1.17(0.81,1.70)$ & 6 & $1.29(0.55,3.03)$ & 22 & $1.07(0.69,1.66)$ & 137 & $0.91(0.76,1.08)$ \\
\hline Missing & & 43 & & 5 & & 32 & & 249 & \\
\hline
\end{tabular}

${ }^{\dagger}$ Adjusted for age at baseline, deprivation, smoking status, BMI, alcohol consumption (except esophageal adenocarcinoma), diabetes, aspirin use and statin use (colorectal cancer only). 
Table 4. Prediagnostic sex hormone concentrations and risk of gastrointestinal cancers in women in the UK Biobank

\begin{tabular}{|c|c|c|c|c|c|c|c|c|c|}
\hline & \multicolumn{3}{|c|}{$\begin{array}{c}\text { Esophageal } \\
\text { adenocarcinoma }\end{array}$} & \multicolumn{2}{|c|}{$\begin{array}{c}\text { Esophageal squamous } \\
\text { cell carcinoma }\end{array}$} & \multicolumn{2}{|c|}{ Gastric cancer } & \multicolumn{2}{|c|}{ Colorectal cancer } \\
\hline & $\begin{array}{c}\text { Person- } \\
\text { years }\end{array}$ & Cases & $\begin{array}{c}\text { Adjusted HR } \\
(95 \% \text { CI })^{\dagger}\end{array}$ & Cases & $\begin{array}{c}\text { Adjusted HR } \\
(95 \% \text { CI })^{\dagger} \\
\end{array}$ & Cases & $\begin{array}{c}\text { Adjusted HR } \\
(95 \% \text { CI })^{\dagger} \\
\end{array}$ & Cases & $\begin{array}{c}\text { Adjusted HR } \\
(95 \% \text { CI })^{\dagger} \\
\end{array}$ \\
\hline \multicolumn{10}{|l|}{ SHBG (nmol/L) } \\
\hline$<39.94$ & 233,639 & 11 & 1.00 & 6 & 1.00 & 20 & 1.00 & 239 & 1.00 \\
\hline 39.94 to $<56.34$ & 230,792 & 9 & $0.89(0.36,2.19)$ & 13 & $1.88(0.70,5.04)$ & 21 & $1.04(0.55,1.96)$ & 210 & $0.91(0.75,1.10)$ \\
\hline 56.34 to $<77.13$ & 218,795 & 8 & $1.91(0.35,2.39)$ & 9 & $1.28(0.44,3.74)$ & 8 & $0.36(0.15,0.88)$ & 219 & $1.01(0.83,1.23)$ \\
\hline$\geq 77.13$ & 178,196 & 8 & $1.21(0.44,3.31)$ & 14 & $2.03(0.72,5.75)$ & 16 & $0.97(0.46,2.01)$ & 171 & $0.97(0.78,1.21)$ \\
\hline \multicolumn{10}{|c|}{ Testosterone (nmol/L) } \\
\hline$<0.54$ & 256,948 & 12 & 1.00 & 19 & 1.00 & 19 & 1.00 & 295 & 1.00 \\
\hline 0.54 to $<0.91$ & 245,946 & 5 & $0.44(0.15,1.23)$ & 16 & $0.89(0.45,1.75)$ & 19 & $1.17(0.61,2.23)$ & 211 & $0.78(0.65,0.93)$ \\
\hline 0.91 to $<1.29$ & 230,301 & 7 & $0.66(0.26,1.67)$ & 5 & $0.33(0.12,0.88)$ & 18 & $1.22(0.63,2.36)$ & 206 & $0.83(0.69,0.99)$ \\
\hline$\geq 1.29$ & 212,509 & 15 & $1.50(0.70,3.24)$ & 9 & $0.66(0.30,1.47)$ & 15 & $1.14(0.57,2.27)$ & 191 & $0.83(0.69,1.00)$ \\
\hline Missing & & 4 & $\mathrm{P}_{\text {trend }}=0.23$ & 2 & $\mathrm{P}_{\text {trend }}=0.09$ & 6 & $\mathrm{P}_{\text {trend }}=0.67$ & 73 & $\mathrm{P}_{\text {trend }}=0.05$ \\
\hline \multicolumn{10}{|c|}{ Free testosterone $(\mathrm{nmol} / \mathrm{L})$} \\
\hline 0.006 to $<0.01$ & 215,286 & 5 & $0.57(0.19,1.69)$ & 10 & $0.65(0.29,1.41)$ & 16 & $1.08(0.54,2.17)$ & 201 & $0.81(0.68,0.98)$ \\
\hline 0.01 to $<0.02$ & 213,233 & 10 & $1.12(0.45,2.77)$ & 10 & $0.70(0.32,1.53)$ & 16 & $1.11(0.55,2.24)$ & 183 & $0.76(0.63,0.92)$ \\
\hline$\geq 0.02$ & 209,615 & 12 & $1.30(0.53,3.20)$ & 4 & $0.32(0.11,0.98)$ & 15 & $1.12(0.54,2.31)$ & 191 & $0.80(0.66,0.97)$ \\
\hline Missing & & 7 & $P_{\text {trend }}=0.35$ & 9 & $P_{\text {trend }}=0.05$ & 13 & $P_{\text {trend }}=0.75$ & 141 & $P_{\text {trend }}=0.01$ \\
\hline \multicolumn{10}{|c|}{ Estradiol (pmol/L) } \\
\hline$<175.0$ & 853,825 & 34 & 1.00 & 45 & 1.00 & 67 & 1.00 & 838 & 1.00 \\
\hline$\geq 175.0$ & 33,918 & 1 & $0.94(0.13,6.94)$ & 0 & - & 0 & - & 20 & $0.85(0.54,1.33)$ \\
\hline Missing & & 8 & & 6 & & 10 & & 118 & \\
\hline
\end{tabular}

${ }^{\dagger}$ Adjusted for age at baseline, deprivation, smoking status, BMI, alcohol consumption (except esophageal adenocarcinoma), diabetes, aspirin use and statin use (colorectal cancer only). 